\title{
A Predictive Atmospheric Tracer Model
}

\author{
By J. Pudykiewicz \\ Atmospheric Environment Service of Canada 2121 Trans Canada Highway, \\ Dorval Quebec, Canada H9P $1 \mathrm{~J} 3$
}

(Manuscript received 9 May 1989, in revised form 29 January 1990)

\begin{abstract}
The global scale predictive tracer model designed to simulate atmospheric transport processes as well as a tropospheric and stratospheric chemistry is described. The model consists of a global spectral model and a set of the mass conservation equations coupled through the chemistry terms. The model was tested in both diagnostic and fully predictive mode simulating the hemispheric scale dispersion of radionuclides from the Chernobyl accident. The analysis of the predictive run results indicate that the model is able to predict the large scale mass distribution for periods up to six days when started from a sufficiently accurate initial condition. An extended prediction of the hemispheric tracer distribution was performed up to 24 days; the tracer field in these experiments was updated every 6 days using an initial condition provided by a parallel run of the diagnostic model.
\end{abstract}

\section{Introduction}

The numerical simulation of many processes in the earth's atmosphere requires the use of predictive tracer models. The best known examples of these include models of tropospheric and stratospheric chemistry employed in the study of acid rain and stratospheric ozone depletion. An additional application of such a model is the simulation of dispersion of radionuclides released accidentally into the atmosphere. The importance of this application became clear following the nuclear disaster at Chernobyl. It was realised that currently available computational resources along with meteorological information available at Numerical Weather Prediction Centers are sufficient for the simulation of radioactive tracers on a synoptic, hemispheric or even global scale (Kimura and Yoshikawa, 1988 and Takasugi and Nakamura, 1988).

This paper will present a formulation of the predictive tracer model developed following the Chernobyl accident. The first Canadian simulation of the Chernobyl dispersion was performed on a hemispheric grid in a pressure coordinate system using a relatively simple 2 -D model. The details of the simulation are described in Pudykiewicz (1988). Following the emergency simulation, extensive development work with the three-Dimensional (3-D) tracer model was conducted. The new model was tested on the Chernobyl case using objectively analysed meteorological fields over a period of one month (Pudykiewicz 1989). The major limitation of the

(C)1990, Meteorological Society of Japan system employed in these studies was the use of observed meteorological fields. Hence, the development of a predictive version of the tracer model is a natural continuation of the previous work. The predictive model developed in the course of this work is now employed for a wide variety of problems requiring the prediction of the transport and transformation of atmospheric tracers. The experimental section of this paper contains results obtained from the application of the predictive model to the Chernobyl release. The predictive model results are also compared to the results obtained from previously performed diagnostic studies.

\section{Formulation of the predictive tracer model}

The models which simulate atmospheric tracers are relatively complex because of the need to represent a wide range of physical and chemical processes. To simulate the interaction between meteorological processes and atmospheric transport of nonconservative species, one needs a set of thermohydrodynamic equations coupled with the mass conservation equations for atmospheric tracers. The system in its most general form could be written as follows:

$$
\begin{aligned}
& d \boldsymbol{U} / d t=\boldsymbol{F}-(1 / \rho) \nabla p-\Pi \boldsymbol{U} \\
& d \ln \rho / d t=-\nabla \boldsymbol{U} \\
& d T / d t=A_{T}+\left(L / c_{p}\right) Q-\left(L / c_{p}\right) E_{o} \\
& p=\rho R T \\
& d q / d t=-Q+E_{o}
\end{aligned}
$$


$d m / d t=Q-\left(P-E_{r}\right)-E_{o}$

$$
\begin{array}{r}
d n^{i} / d t=S^{i}\left(n^{i}, \ldots, n^{M}, m, T\right) \\
(i=1, \ldots, M)
\end{array}
$$

where the symbols have the following meanings:

$\boldsymbol{U}$ - velocity field, $\boldsymbol{F}$-mass forces, p-atmospheric pressure,

$\Pi$ - operator representing turbulent mixing, $\rho$-density,

$\nabla$ - gradient operator, T-temperature, R-gas constant,

q - mixing ratio of water vapour, L-latent heat constant,

$A_{T}$ - dynamic part of tendency rate for temperature,

$\mathrm{Q}$ - latent heat of condensation, $E_{o}$-evaporation, m-cloud water,

$\mathrm{P}$ - precipitation rate, $E_{r}$-evaporation of rain, $n^{i}$-mixing ratio for atmospheric trace species, $S^{i}($ )-source and sinks for atmospheric trace species, $\mathrm{d} / \mathrm{dt}$-material derivative $(d / d t=\partial / \partial t+\boldsymbol{U} \circ \nabla)$, M-number of atmospheric trace species simulated in the model

The system (1) $-(7)$ consists of $(8+M)$ equations and simulates the meteorological processes and chemical reactions of atmospheric trace species. The boundary conditions for the dynamical and chemical part of the system have to be specified, and they depend on the particular geometry of the domain being considered.

The first eight equations of the system are in fact a nonhydrostatic meteorological model. The model equations include the bulk representation of microphysical processes such as condensation, the formation of clouds and precipitation and the evaporation of rain. The atmospheric boundary layer processes are represented by the operator $\Pi$ which takes into account the momentum transfer by convective processes and by dynamically generated turbulence. The set of Eq. (7) represents a nonlinear atmospheric chemistry. The set given by Eqs. (1)(7) is designed mostly for application on a regional scale and is far too complex for most applications involving the simulation of atmospheric processes on a hemispheric or global scale. One common simplification is to assume hydrostatic equilibrium (Kasahara, 1977). This approximation leads to a tracer model driven by a primitive equations meteorological model (Pudykiewicz et al., 1985).

The large scale predictive tracer model used in this study is, in fact, a set of tracer equations coupled to a spectral model (Daley et al., 1976). In general, this coupled set of models was designed for the simulation of tropospheric and stratospheric transport and chemistry. Formally, the equations of the predictive tracer model employed could be written as follows:

$$
\begin{aligned}
& \partial \zeta / \partial t=-\nabla \circ(\zeta+f) \boldsymbol{V}-k \circ \nabla \\
& \times(R T \nabla \pi+\dot{\sigma} \partial \boldsymbol{V} / \partial \sigma-\boldsymbol{F}) \\
& \partial D / \partial t=k \circ \nabla \times(\zeta+f) \boldsymbol{V}-\nabla \circ(R T \nabla \pi \\
& +\dot{\sigma} \partial \boldsymbol{V} / \partial \sigma-\boldsymbol{F})-\nabla^{2}(\Phi+\boldsymbol{V} \circ \boldsymbol{V} / 2) \\
& \partial T / \partial t=-\nabla \boldsymbol{V} T+T D+\dot{\sigma} \gamma \\
& -\left(R T / C_{p}\right)(D+\partial \dot{\sigma} / \partial \sigma)+\boldsymbol{H}_{T} \\
& \partial \pi / \partial t=-D-\partial \dot{\sigma} / \partial \sigma-\boldsymbol{V} \circ \nabla \pi \\
& \sigma \partial \Phi / \partial \sigma=-R T \\
& \partial q / \partial t=-\boldsymbol{V} \nabla q-\dot{\sigma} \partial q / \partial \sigma-Q+E_{o} \\
& \partial \phi^{i} / \partial t=-\boldsymbol{V} \nabla \phi^{i}-\dot{\sigma}\left(\partial \phi^{i} / \partial \sigma\right)+v_{\boldsymbol{g}}^{i}\left(\partial \Gamma \phi^{i} / \partial \sigma\right) \\
& +\partial / \partial \sigma\left(\Gamma^{2} K_{z} \partial \phi^{i} / \partial \sigma\right)+\boldsymbol{S}^{i}\left(\phi^{i}, \ldots, \phi^{M}, \boldsymbol{X}\right)(14)
\end{aligned}
$$

where:

$f \quad$ - Coriolis parameter

$\boldsymbol{V}$ - horizontal vector wind

$\zeta$ - vertical component of vorticity $=\mathrm{k} \circ \nabla \times \boldsymbol{V}$

$D$ - horizontal divergence $=\nabla \boldsymbol{V}$

$T$ - temperature

$\gamma \quad$ - static stability $=R T / C_{p} \sigma-\partial T / \partial \sigma$

$\dot{\sigma} \quad$ - vertical motion in the $\sigma$ coordinate system

$\Phi \quad$ - geopotential height

$\boldsymbol{F}$ - horizontal frictional force per unit mass

$\boldsymbol{H}_{T}$ - diabatic heating

$R$ - gas constant for dry air

$C_{p}$ - specific heat of dry air at constant pressure

$\phi^{i}$ - mixing ratio or specific activity of the i-th tracer

$S^{i} \quad$ - source and sinks term for i-th specie (in general this term is related to the atmospheric chemistry).

$v_{g}^{i} \quad$ - gravitational settling velocity

$\Gamma=g \sigma / R T$

$g \quad$ - acceleration due to gravity

$R$ - specific gas constant of air

$K_{z}$ - vertical diffusion coefficient

The model described by Eqs. (8)-(13) is the Canadian Meteorological Center's operational spectral model which is used to produce hemispheric weather forecasts for up to 6 days. The model uses a triangularly truncated set of spherical harmonics with the truncation at eighty-nine waves (T89). Sixteen levels are used in the terrain following $\sigma$-coordinate system. Dynamic and thermodynamic variables are 
defined on staggered levels. The vertical discretization of the primitive meteorological equations is accomplished with a piecewise constant finite-element scheme. The time discretization employed in the model is semi-implicit with a typical time step of 20 minutes. The physical processes parameterized in the model include turbulent vertical fluxes, horizontal diffusion, stable and convective precipitation and radiative heating.

Turbulent vertical fluxes of momentum, heat and moisture in the surface layer are calculated from similarity theory. Turbulent exchange above the constant flux layer is represented using eddy diffusion coefficients which are functions of vertical wind shear and static stability. Small scale horizontal mixing is parameterized using a weak biharmonic diffusion scheme for momentum, temperature and dry static energy.

Stable and convective precipitation are included as one of the most important physical processes simulated by the model. Stable precipitation is currently calculated by removing the excess of moisture above some threshold value of relative humidity. The moist convection is parameterized following Kuo (1974). Cloud cover required in the calculation of radiative heating is obtained as a function of the local relative humidity.

Surface temperature in the spectral model is calculated by solving an energy balance equation over land; over water, surface temperature is obtained from climatological data.

The tracer model consist of the set of Eq. (14) coupled with the primitive meteorological equations. For the purposes of this work, the set of advectiondiffusion Eq. (14) was rewritten in the following general form:

$$
\partial \bar{A}^{i} / \partial t=\left(L_{1}+L_{2}+\Pi_{\sigma}+\bar{S}_{A}^{i}\right) \bar{A}^{i}
$$

where: $L_{1}, L_{2}, \Pi_{\sigma}, \bar{S}_{A}^{i}$ are operators representing the horizontal and vertical advection, turbulent mixing and sources and sinks respectively, $\bar{A}^{i}$ specific activity of i-th isotope.

The explicit form of the operators $L_{1}, L_{2}, \Pi_{\sigma}$ and $\bar{S}_{A}^{i}$ could be written as follows:

$$
\begin{aligned}
L_{1} & :=-V_{H}^{\sigma} \nabla_{H}^{\sigma} \\
L_{2} & :=-\dot{\sigma} \partial / \partial \sigma+\left(v_{g}^{i} \partial / \partial \sigma\right) \Gamma \\
\Pi_{\sigma} & :=\partial / \partial \sigma\left(\Gamma^{2} K_{z} \partial / \partial \sigma\right) \\
\bar{S}_{A}^{i} & =Q^{i}-W\left(\bar{A}^{i}\right)+D_{i j} \bar{A}^{j}
\end{aligned}
$$

where: $Q^{i}$ - source term, $W\left(\bar{A}^{i}\right)$-wet scavenging term

$D_{i j}-\mathrm{M}^{*} \mathrm{M}$ matrix describing the transformation of the isotopes and radioactive decay
The time discretization of (15) is performed by successively applying the operators $L_{1}, L_{2}, \Pi_{\sigma}$ and $\bar{S}_{A}^{i}$ to advance a time step $\Delta t$ and then successively applying the operators in reverse order to advance a further time step. In our simulation, the operators $L_{1}$ and $L_{2}$ were approximated using the semiLagrangian technique (Robert 1982) which has the advantage of being absolutely stable even when the time step used for numerical integration is relatively long. The scheme employed is described by Ritchie (1987).

The vertical diffusion is solved using the implicit method described by Concus et al., (1976). The solution is subject to the following boundary conditions:

$$
\begin{aligned}
& K_{z} \Gamma^{2} \partial \bar{A}^{i} / \partial \sigma=\alpha^{i} \Gamma \bar{A}^{i}+\beta^{i} \Gamma \text { for } \sigma=\sigma_{B} \\
& K_{z} \Gamma^{2} \partial \bar{A}^{i} / \partial \sigma=0 \text { for } \sigma=\sigma_{T}
\end{aligned}
$$

where: $\sigma_{B}, \sigma_{T}-\sigma$ at the bottom and at the top of the model domain respectively, $\alpha_{i}$ - deposition velocity for the i-th specie $\left(\alpha_{i}=v_{d}^{i}\right)$

$\beta_{i}$ - surface emission flux for the i-th specie.

The profile of the vertical diffusion coefficient required to solve the vertical diffusion problem is computed using the following cubic spline formulae:

$$
\begin{aligned}
K_{z} & =K_{h}+\left(\frac{z-h}{H-h}\right)^{2} *\left\{K_{h}-K_{H}\right. \\
& \left.+(z-h) *\left[\left(\frac{\partial K_{z}}{\partial z}\right)_{h}+2 * \frac{K_{h}-K_{H}}{H-h}\right]\right\}
\end{aligned}
$$

where:

$\left(\frac{\partial K_{z}}{\partial z}\right)_{h}$ - derivative of the diffusion coefficient at the top of the surface layer

$h, H \quad$ - height of the surface layer and the Planetary Boundary Layer respectively

$K_{h}, K_{H}$ - vertical diffusion coefficient at the top of the surface layer and at the top of Planetary Boundary Layer (PBL) respectively

The values of: $\left(\frac{\partial K_{z}}{\partial z}\right)_{h}, K_{h}, K_{H}, h$ and $H$ are calculated in the spectral model according to the described parameterization of physical processes.

The deposition velocity appearing in the boundary condition is computed as the inverse of the sum of the resistance of the turbulent and laminar deposition layers and the resistance of the surface (Chamberlain and Chadwick, 1965):

$$
v_{d}=\frac{1}{r_{a}+r_{d}+r_{s}}
$$

where: 


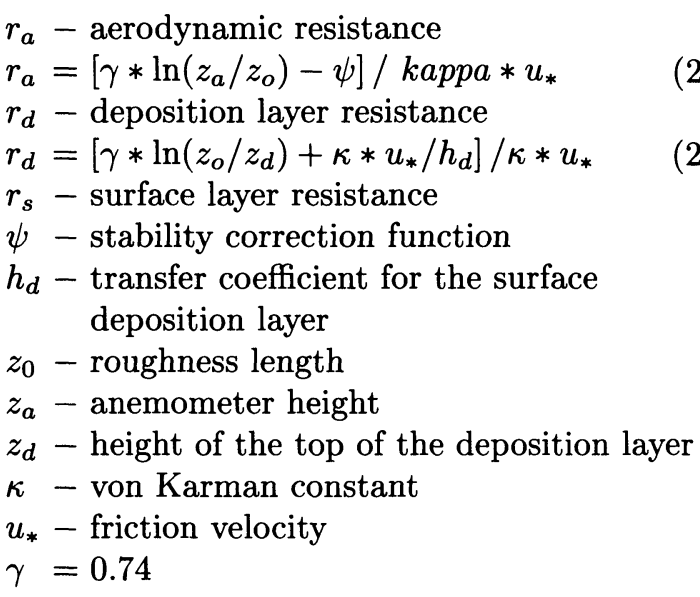

The last substep in the solution of Eq. (15) is accomplished using the analytical solution of the following equation:

$$
\partial \bar{A}^{i} / \partial t=Q^{i}-W\left(\bar{A}^{i}\right)+D_{i j} \bar{A}^{j}
$$

The general form of the matrix $\mathrm{D}$ is as follows:

$$
D_{i j}=\left|\begin{array}{ccc}
G_{1} & & 0 \\
& \ddots & \\
0 & & G_{L}
\end{array}\right|
$$

where: L-is the number of decay chains considered in the simulation, and $\mathrm{G}$ is a two - diagonal matrix corresponding to the m-th decay chain:

$$
\begin{aligned}
G_{m}= & \left|\begin{array}{ll}
-\lambda_{1}^{m} & \\
\lambda_{1}^{m}-\lambda_{2}^{m} & 0 \\
0 & \lambda_{k-1}^{m}-\lambda_{k}^{m}
\end{array}\right| \\
\lambda_{i}^{m} & \begin{array}{r}
\text { radioactive decay constant for the i-th } \\
\quad \text { step in the m-th decay chain. }
\end{array} \\
k & \text { - number of the steps in the decay chain }
\end{aligned}
$$

Wet scavenging is represented by the term $W\left(\bar{A}^{i}\right)$ in Eq. (26). Considering the fact that the spectral model employs a relatively simple parameterization of cloudiness, we decided to use a statistical parameterization of the wet scavenging term described by the following relation:

$$
W^{i}= \begin{cases}0 & \text { for } \quad U<U_{o} \\ \mathrm{~A}\left(\frac{U-U_{o}}{U_{s}-U_{o}}\right) & \text { for } \quad U \geq U_{o}\end{cases}
$$

where:

$U$ - relative humidity predicted by the spectral model

$U_{o}$ - threshold value of the relative humidity above which the subgrid scale condensation occurs $\left(U_{o}=0.8\right)$

$U_{s}$ - relative humidity for the saturation state $\left(U_{s}=1.0\right)$

$\Lambda$ - constant, $\Lambda=3.5^{*} 10^{-5} s^{-1}$
The parameterization employed is the rain-out type and does not take into account the difference between removal by stratiform and convective clouds. The scheme given by (29) is thus restricted to large scale application. In general, a realistic parameterization of wet scavenging could be obtained only by applying a fully predictive cloud water scheme carring explicit information about cloud and precipitating water at all model levels (Sundqvist, 1981). The spectral model employed in this study is not equipped with this scheme. Future modification of the parameterization of wet scavenging is therefore dependent on the appropriate modification of the spectral model.

The predictive tracer model described in this chapter was obtained by coupling the spectral model with a set of advection-diffusion equations. The resulting system permits simulation of the transport processes and meteorological variables within one system. The boundary layer parameters, cloud cover and relative humidity are computed internally in the predictive tracer model. It is therefore possible to avoid expensive diagnostic calculations. This is an advantage of the fully predictive approach over a diagnostic model such as the one described in Pudykiewicz (1989). The performance of the predictive tracer model will be presented in the following chapters.

\section{Testing of the predictive tracer model}

Atmospheric transport over large distances is a very complex process. In most instances, the only way of assessing the accuracy of the transport model is by simulating the release of a well defined tracer. In order to evaluate our predictive tracer model we decided to employ it for the simulation of the Chernobyl release. The selection of the Chernobyl release for verification of the predictive tracer model is justified by the availability of a large number of observations and the extensive literature related to this subject. In addition, it is important to test the predictive power of the model on the simulation of a real case involving a nuclear emergency when the application of predictive meteorology could be of critical significance.

The atmospheric tracer model was executed for a period of 4 weeks, starting on April 25 1986, the first day of the release. The emission scenario employed in the computer simulation is quite complex. The release of radioactivity from the Chernobyl reactor occurred as a continous process over a nine-day period. The initial release immediately following the explosion in the reactor accounted only for $25 \%$ of the total radionuclides injected into the atmosphere. After an extensive analysis of the observations of radioactivity in the surroundings of the Chernobyl reactor, it was concluded that there were four distinct stages in which radionuclides were released. The ini- 
tial stage was a very intensive release on the first day of the accident. During the following five days, the release rates declined steadily to a minimum value six times lower that the initial release rate. This decline in the amount of material injected into the atmosphere was then followed by a four-day period of increase to reach a level of $70 \%$ of the initial release rate. The last stage of the process took place 9 days after the accident when the release was reduced to $1 \%$ of its initial value.

The amount of release was estimated on the basis of radiation measurements and various technical analyses of samples taken from the vicinity of the Chernobyl reactor. It was concluded that about $1 *$ $10^{18}$ to 2 . $* 10^{18} \mathrm{~Bq}\left(3 . * 10^{7}-5\right.$. $\left.* 10^{7} \mathrm{Ci}\right)$ were discharged to the atmosphere from the core of the Chernobyl reactor. This estimate dose not include the release of xenon and krypton, which were completely expelled from the fuel. The observation indicated that about $20 \%$ of volatile radionuclides like Iodine, Cesium and Tellurium were expelled from the damaged reactor. It is commonly accepted that the error of estimate of the Chernobyl release is \pm 50 $\%$. The total daily releases of radionuclides without noble gases are shown in Table 1 . The data in Table 1 are calculated for May 6, 1986 taking radioactive decay into account. Experimental data indicate intermittent changes in the composition of the release. As a first approximation, we assumed that each isotope varied in time proportionally to the total release.

The source term- $\mathrm{Q}^{i}$ appearing in Eq. (19) was approximated using the concept of the 3Dimensional virtual source. The release in this approximation is represented by a function of three spatial variables and time:

where:

$$
\begin{array}{r}
Q^{i}\left(\eta_{x}, \eta_{y}, \sigma, t\right)=\left(\left(E^{i}(t) F(\sigma)\right) /\left(2 \pi \sigma_{H}^{2}\right)\right) \\
\operatorname{Exp}\left[-r^{2} / 2 \sigma_{H}^{2}\right]
\end{array}
$$

where:

$$
\begin{aligned}
& E^{i}(t) \text { - amount of the radioactivity released } \\
& F(\sigma)-f(\sigma) *\left(\frac{R T}{\sigma \pi}\right) *\left\{\int_{\sigma_{T}}^{\sigma_{B}} f(\sigma)\left[\frac{R T}{g \sigma}\right] d \sigma\right\}^{-1} \\
& f(\sigma) \text { - function describing the vertical distri- } \\
& \text { bution of the release } \\
& \left(\eta_{x}^{o}, \eta_{y}^{o}\right) \text { - coordinates of the source of the } \\
& \text { release } \\
& r \quad=\left(\left(\eta_{x}^{o}-\eta_{x}\right)^{2}+\left(\eta_{y}^{o}-\eta_{y}\right)^{2}\right)^{1 / 2} \\
& \sigma_{H} \quad \text { - standard deviation of the horizontal } \\
& \text { mass distribution }\left(\sigma_{H}=1.5 * 10^{5} \mathrm{~m}\right) \\
& R \quad \text { - specific gas constant of air } \\
& T \text { - temperature }
\end{aligned}
$$

The effective height of the release was a function of time, changing from $4000 \mathrm{~m}$, just after the explosion, to $1500 \mathrm{~m}$ subsequently. The initial height of
Table 1 . The daily release of radionuclides to the atmosphere during the Chernobyl accident

\begin{tabular}{ccc}
\hline date & $\begin{array}{c}\text { time after accident } \\
\text { in days }\end{array}$ & release $10^{6} \mathrm{Ci}$ \\
\hline $26-04-1986$ & 0 & 12.0 \\
$27-04-1986$ & 1 & 4.0 \\
$28-04-1986$ & 2 & 3.4 \\
$29-04-1986$ & 3 & 2.6 \\
$30-04-1986$ & 4 & 2.0 \\
$01-05-1986$ & 5 & 2.0 \\
$02-05-1986$ & 6 & 4.0 \\
$03-05-1986$ & 7 & 5.0 \\
$04-05-1986$ & 8 & 7.0 \\
$05-05-1986$ & 9 & 8.0 \\
$06-05-1986$ & 10 & 0.1 \\
\hline
\end{tabular}

$4000 \mathrm{~m}$ was assumed to be in direct response to the initial explosion Pudykiewicz (1988). The smaller vertical extension of $1500 \mathrm{~m}$ which was assumed during the days following the accident, mostly reflects the intensive convection over the burning reactor and subgrid-scale vertical mixing of radioactive material in the lower part of the troposphere.

The tracer Eq. (15) was solved initially using data stored in the archiving system of the Objective Analysis (OA) at the Canadian Meteorological Center (CMC) (Rutherford, 1977). The analysis of meteorological fields at the time of the accident was performed every 6 hours on a gaussian latitudelongitude grid with a resolution of $128^{*} 32$ points over the Northern Hemisphere. The meteorological fields for intermediate time levels were obtained by time interpolation. The verification of the results from the diagnostic model was performed for a network covering the Northern Hemisphere and indicates that the simulation was quite accurate. The simulated times of arrival and times of arrival of maximum activity agree quite well with the observed values. The ratio of the time average activity simulated by the model and obtained from the measurements varies between 0.21 and 2.80 with a mean value of 1.05 (Pudykiewicz 1989).

The results of calculations performed with analysed meteorological fields represent an ideal situation which cannot possibly be achieved in a predictive mode because of inherent errors in the $\mathrm{Nu}$ merical Weather Prediction (NWP) models. However, the good accuracy of the simulation performed with the diagnostic tracer model raises the question: "What is the maximum range of the predictability of the transport of radioactive tracers on the synoptic and hemispheric scale?"

The test of the predictive model began with an attempt to predict the transport of I-131 released from the Chernobyl reactor during the 7 days fol- 

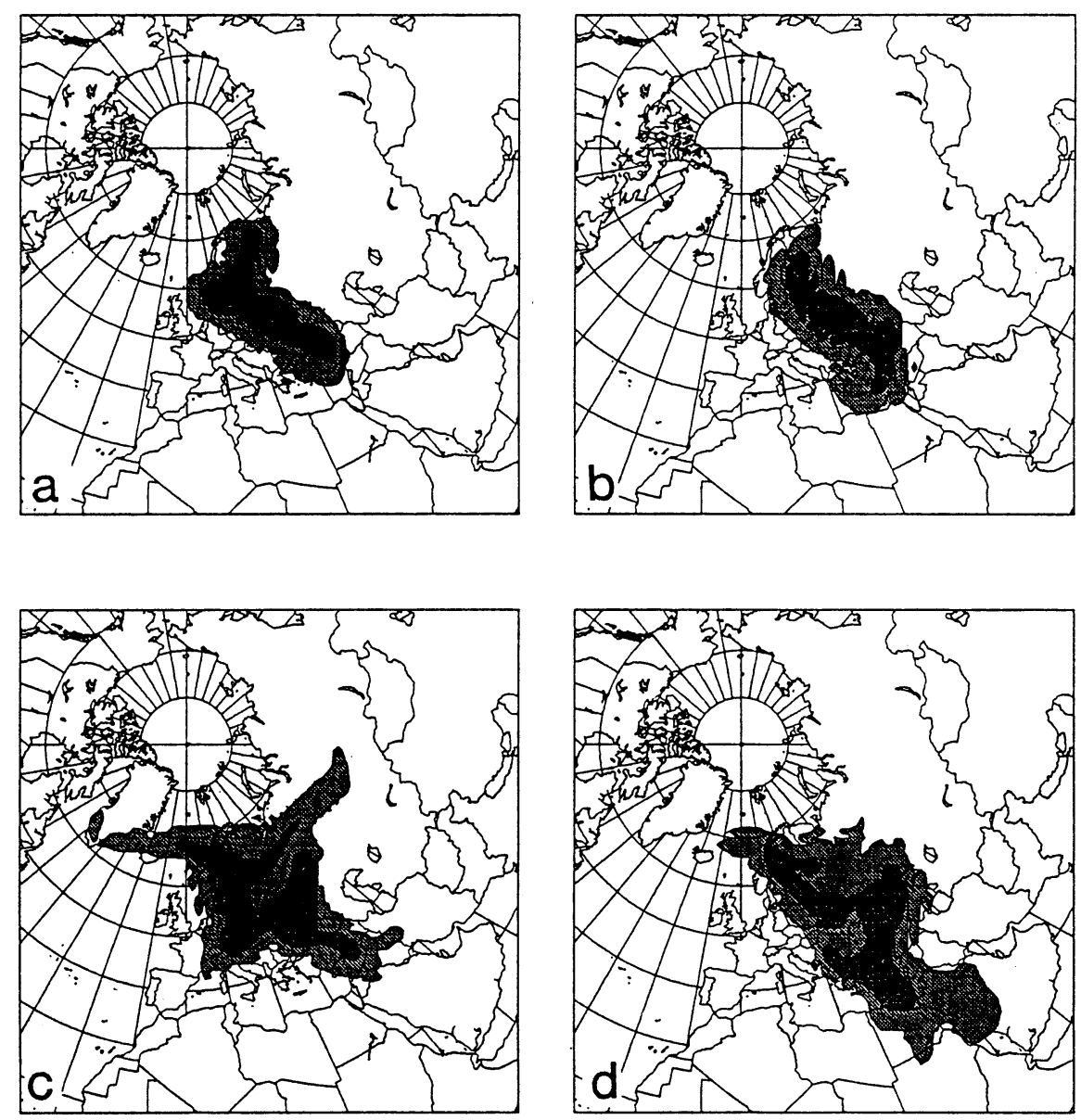

Fig. 1. Predicted versus diagnosed activity fields of I-131 at $\sigma=1$ over Europe. a) diagnosed activity field on April 28, 19861800 GMT, b)activity field predicted for $48 \mathrm{hrs}$., valid on April 28, 19861800 GMT. c) diagnosed activity field on April 30, 19861800 GMT, d) activity field predicted for 96 hrs., valid on April 30, 19861800 GMT.

lowing the accident. The model employed had a triangular truncation of T89 and the corresponding hemispheric gaussian grid had a resolution of $288 \times 72$. The tracer model was started using analyzed meteorological fields for 1800 GMT, April 25, 1986, the I-131 field was initially set to zero. The source term was turned on at the moment of the accident, namely at 2100 GMT and had exactly the same form as in the diagnostic simulation.

The results of the diagnostic calculations indicate that during the first two days following the Chernobyl accident, the radioactive cloud was transported mostly towards Scandinavia. A second southern segment of the cloud had spread southeastward over the Black Sea in the direction of the Middle East. The position of the radioactive cloud near the surface is depicted in Fig. 1a. On April 28 the northern part of the radioactive cloud moved southward, crossing central Europe. Subsequently on April 29, a well developed westerly flow began to transport radioactive material across the USSR (Fig. 1c).

The results of the predictive run for $48 \mathrm{hrs}$ and 96 hrs are presented in Fig. 1b and 1d. It is shown that the 2 day prediction has relatively good accuracy, as the model was quite good in predicting the main directions of the transport. However, the quality of the 4 day prediction deteriorated substantially. The deficiency of the predictive model is manifested mostly by the lack of radioactive material over western Europe, Fig. 1b and 1d. It is obvious that the value of the prediction beyond $4-5$ days is very small in this case. The first run of the predictive model shows, however, that we can predict the distribution of the tracer on a regional scale for the first $2-3$ days after the release. The development of a system capable of producing an accurate mesoscale and regional scale prediction must await future enhancements of global models and increased sophistication of regional NWP models.

In order to investigate the performance of the predictive tracer model on a larger scale, we decided to continue the run of the predictive model starting from 1800 GMT May 1, 1986. The meteorological part of the initial condition was provided by the objective analysis of the Canadian Meteorological 

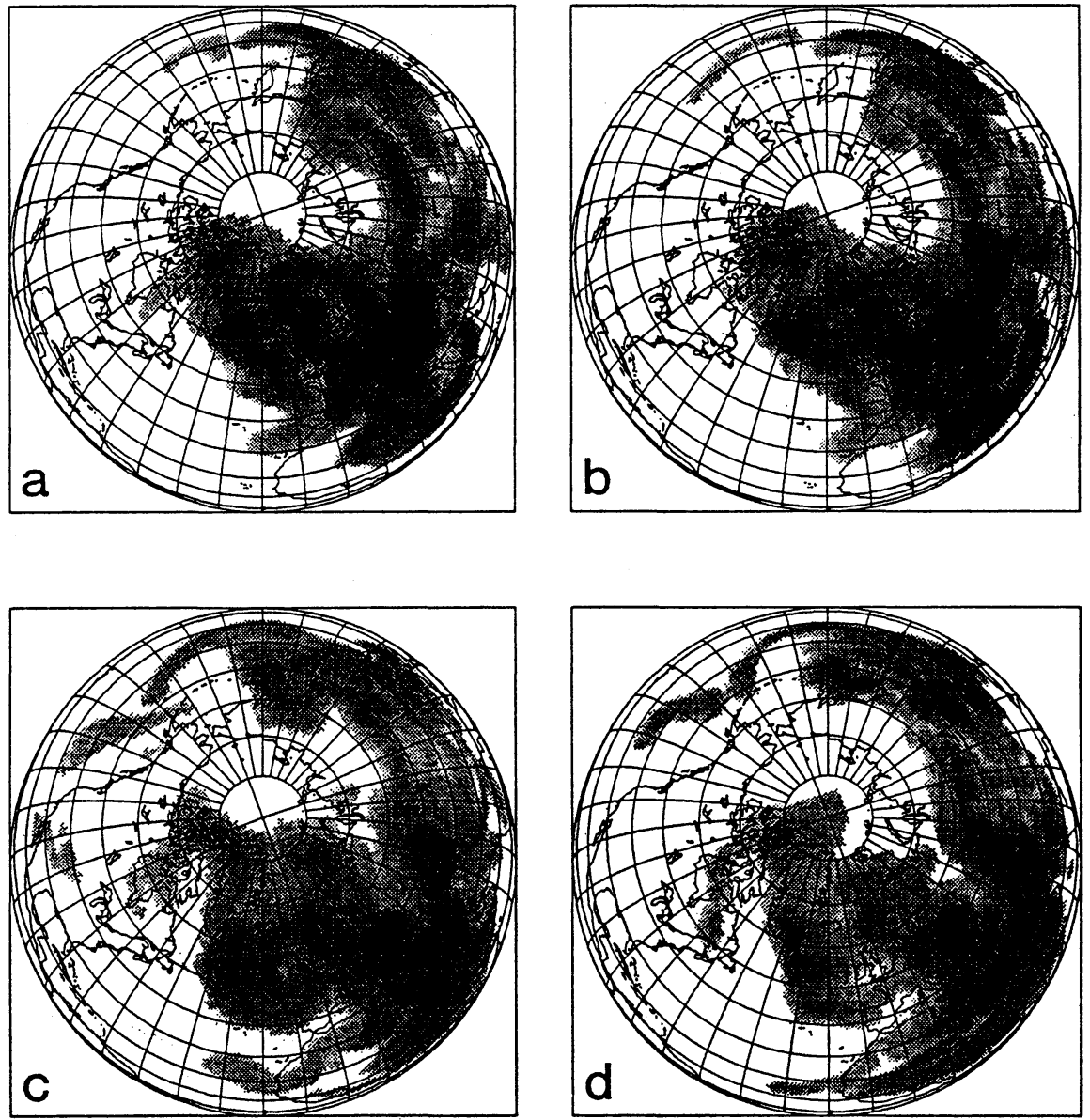

Fig. 2. Predicted versus diagnosed activity fields of I-131 at $\sigma=1$ over the Northern Hemisphere a) diagnosed activity field on May 3, 19861800 GMT, b)activity field predicted for $48 \mathrm{hrs}$., valid on May 3, 19861800 GMT. c) diagnosed activity field on May 5, 19861800 GMT, d) activity field predicted for 96 hrs., valid on May 5, 19861800 GMT.

Center whereas the initial conditions for the tracer field were obtained from the diagnostic run. In other words, the procedure was to use observations to update the meteorological part of the system and a parallel diagnostic run to initialize the tracer part. In the following step, the model was integrated forward in time in order to produce a prediction of the tracer distribution. This particular form of the execution of our tracer model will be called "mixed mode" because of the use of the diagnostic model to provide the initial condition for the tracer field.

The comparison of the diagnostic and mixed mode results for May 3 and 5 at 1800 GMT is depicted in Fig. 2. It is shown that the prediction for 2 days (Fig. 2b) and 4 days (Fig. 2d) starting from the large scale tracer distribution on May 1 is correlated quite well with the diagnostic model results. Also, one notices that the tracer model employed in the mixed mode correctly predicts the two major directions of transport of radioactive material to the Western Hemisphere. The characteristic circular distribution of mass over Greenland and the Atlantic Ocean was also predicted quite well by our tracer model. The other main features reproduced by the predictive model are the injection of the radioactive material through the Canadian arctic to Northern Quebec and the transport of material in the westerly flow over the Pacific ocean. On May 7, after the dissipation of the low over northern Quebec, the radioactive material over the arctic region moved rapidly southeastwards passing through Ontario, Quebec and the Atlantic provinces of Canada. The descending motions on the western side of the radioactive cloud brought down a small amount of the material from the higher levels. The radioactive material appeared along the west coast from Vancouver (British Columbia, Canada) to Alaska and over the southwestern states of the USA. The corresponding comparison of the diagnostic and predictive runs is shown in Fig. 3. It is shown again that the 6 days prediction is surprisingly accurate concerning the large scale patterns.

The updating procedure for the tracer field was then repeated for the next two 7 day intervals. Fig. $4 \mathrm{~b}$ and $4 \mathrm{~d}$ show the two and four day predictions performed using the tracer field valid 1800 GMT, 

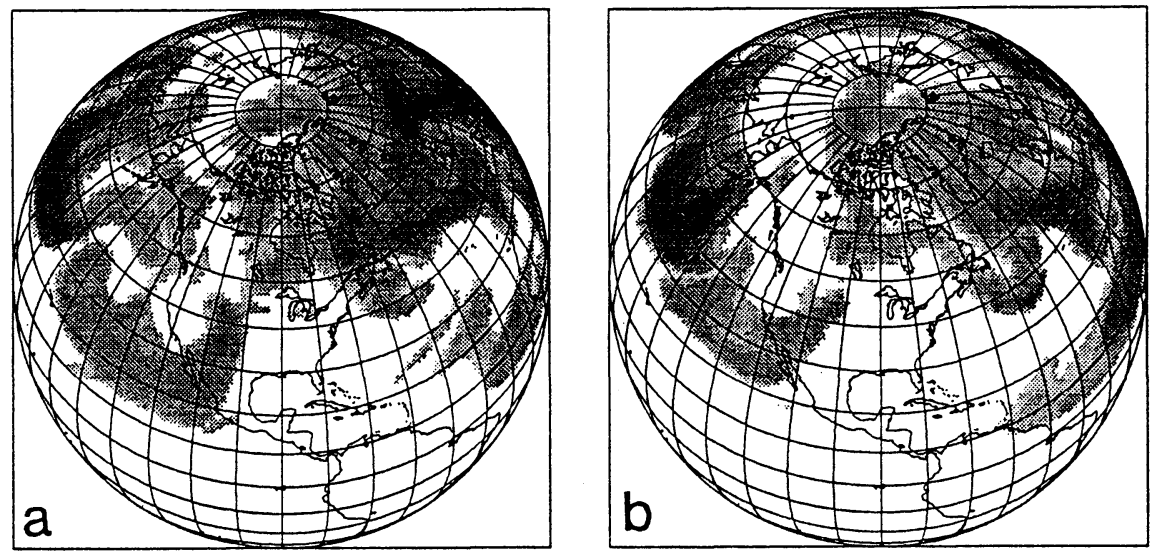

Fig. 3. Predicted versus diagnosed activity fields of I-131 at $\sigma=1$ over the Northern Hemisphere a) diagnosed activity field on May 7, $19861800 \mathrm{GMT}$, b) activity field predicted for $144 \mathrm{hrs}$., valid on May 7, 19861800 GMT.
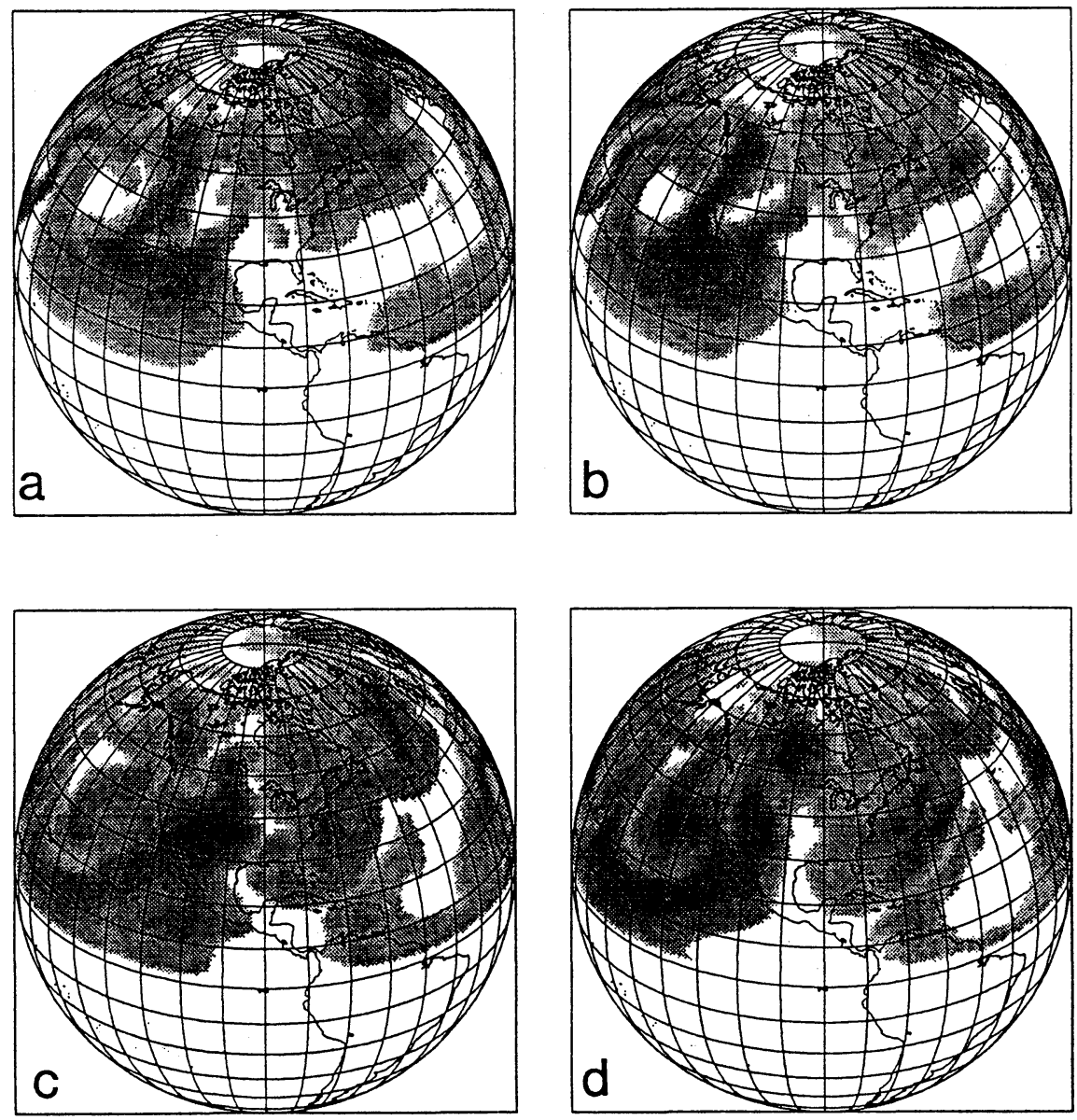

Fig. 4 Predicted versus diagnosed activity fields of I-131 at $\sigma=1$ over the Northern Hemisphere a) diagnosed activity field on May 9, 19861800 GMT, b) activity field predicted for $48 \mathrm{hrs}$., valid on May 9, 1986 1800 GMT. c) diagnosed activity field on May 11, 19861800 GMT, d) activity field predicted for 96 hrs., valid on May 11, 19861800 GMT.

May 7 as the initial condition. It is shown that after May 8 , the radioactive cloud attained hemispheric scale due to eddy-like mixing by the synoptic scale low pressure systems superposed with the average zonal flow. The cloud viewed on a hemispheric scale essentially shows a pattern analogous to turbulent diffusion, with low pressure systems acting as mixing eddies. It is important to note that the patterns 

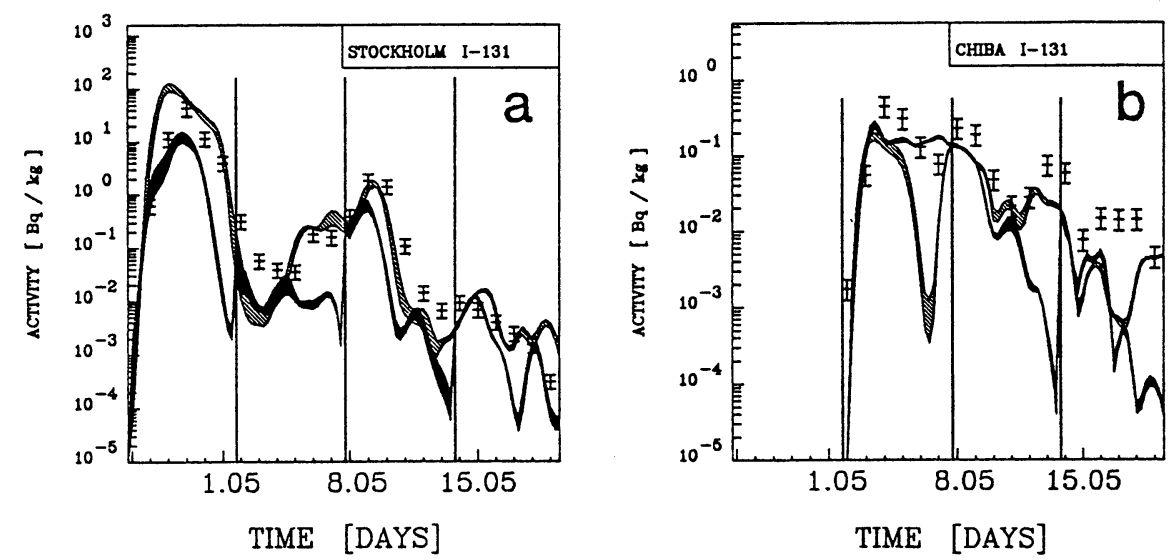

Fig. 5. Comparison of the observed, predicted and diagnosed time series of I-131 activity in: a) Stockholm, b) Chiba (located on Honshu Island, Japan). The measured values are represented by vertical bars. The diagnostic model results correspond to the dashed area between the two lines, and the predictive model results are represented by the black area. The two lines depicting the model results take into account the uncertainty of the sampling process.

obtained from the forecast and diagnostic modes are again in relatively good agreement (Fig. 4).

The analysis of the results described here shows that the prediction of the large scale distribution of the I-131 was more accurate than the initial predictions on the regional scale. This fact could be attributed partially to the poor accuracy of the initial medium range forecast on a regional scale. It is more certain however, that the better performance of the model on the hemispheric scale could be explained by the good accuracy of the meteorological prediction of the synoptic scale patterns.

\section{Verification of the predictive model results}

The measurements of radioactivity performed following the Chernobyl accident provide a unique data base for extensive verification studies of atmospheric models. In this paper, we present the preliminary verification of the predictive tracer model against measurements from a network covering most of the Northern Hemisphere. The model verification on this scale is very important because it is difficult to estimate the predictive power of the system given by Eqs. (8)-(14) on the basis of the regional tracer studies only. In most cases, regional scale tracer experiments are limited by the size of the domain under consideration. The influence of lateral boundary conditions is often a factor limiting our ability to evaluate models over time intervals of the order of several weeks. In this study, the influence of lateral boundary conditions was not present because during the 4 week period considered, the interhemispheric exchange of radionuclides was negligible.

Verification of the predictive model presented in this paper was performed for the surface activities of I-131. The predicted activities are also compared to the results obtained from previous diagnostic calculations (Pudykiewcz, 1989).
The verification results are presented in the form of graphs displaying time series of the measured and simulated activities. The predictive model verification for Stockholm is shown in Fig. 5a as the black area between the two lines representing the lower the upper model bounds. The model bounds for the experimental point located within a particular grid cell are defined by the following formulas:

$$
\begin{aligned}
& f_{L}(t)=f_{M}(t)-f_{\delta}(t) \\
& f_{U}(t)=f_{M}(t)+f_{\delta}(t) \\
& f_{M}(t)=\sum_{k=1}^{n} \alpha_{k} f^{(k)}(t), n=4 \\
& f_{\delta}(t)=\left\{\left[\sum_{k=1}^{n}\left(f_{M}(t)-f^{(k)}(T)\right)^{2}\right] /(n-1)\right\}^{1 / 2}
\end{aligned}
$$

where:

$$
\begin{aligned}
& f_{L}(t), f_{U}(t) \text { - lower and upper bounds of the } \\
& f^{(k)}(t) \quad-\text { the grid point values from the } \\
& \alpha_{k} \quad-\text { the weights of interpolation }
\end{aligned}
$$

The diagnostic model results are represented by the dashed belt between the lower the upper model bounds. The measured values of the activity at the surface are represented by the vertical error bars. For display purposes, we assumed that the error is $30 \%$, as was done in the paper describing the 2-D model results (Pudykiewicz, 1988).

The tracer model described here simulates gridcell average values of specific activity with the incorporation of wet scavenging by cloud systems resolvable by the grid system. The subgrid scale wet 

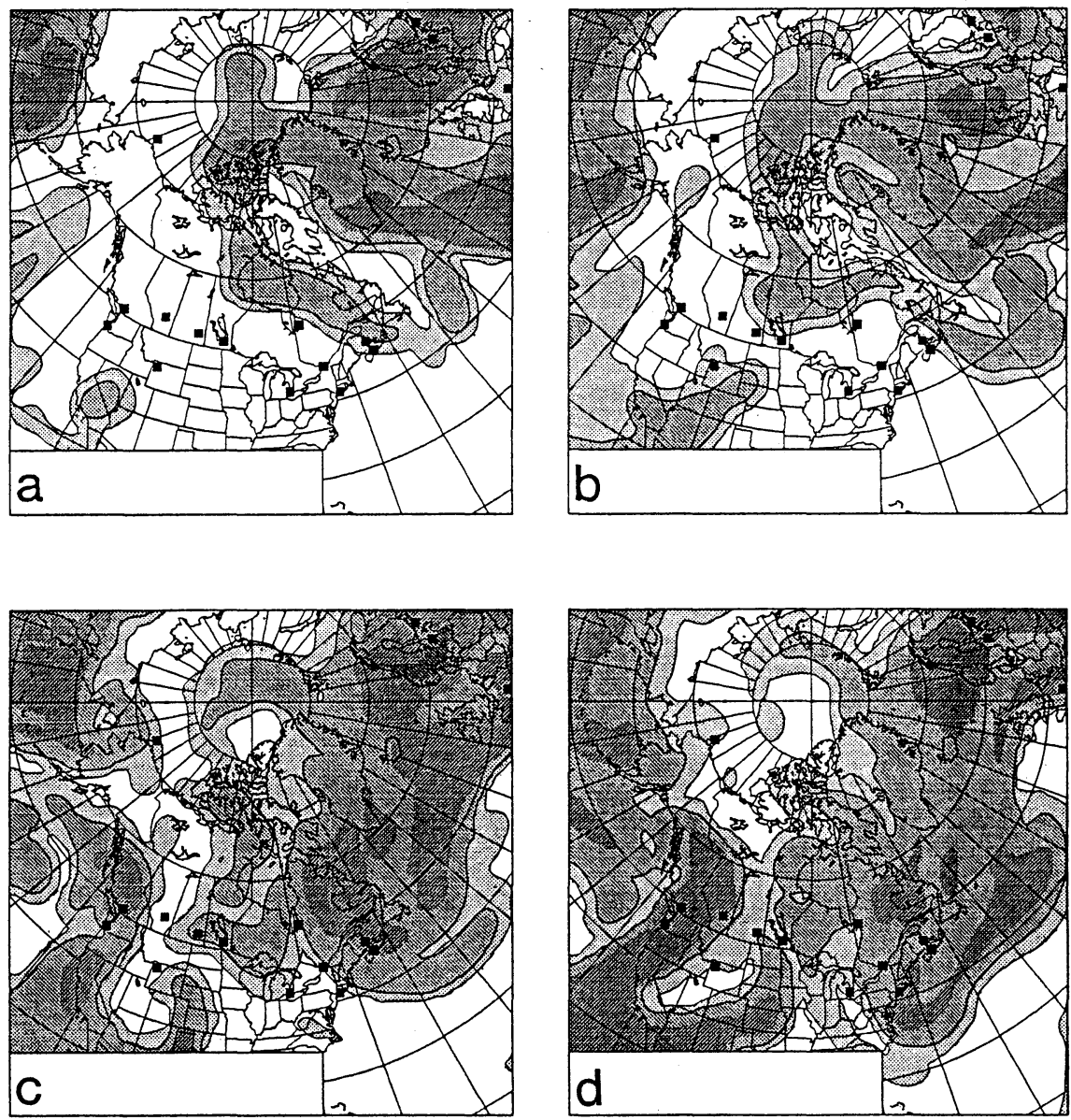

Fig. 6 . Predicted activity field (bq kg ${ }^{-1}$ ) for $\mathrm{I}_{131}$ at $\sigma=1$ over North America on a) 6 May, b) 7 May, c) 8 May and d) 9 May 1986, 1800 GMT. The activity field in the range from $10^{-4}$ to $1 \mathrm{~Bq} \mathrm{~kg}^{-1}$ are displayed. The activity level corresponds to the density of the graphical pattern.

removal by mesoscale precipitation systems is not represented in the simulation.

When comparing the observed and predicted specific activities, it was assumed that the observations are representative of the synoptic scale. The mesoscale meteorological processes certainly affected the observed values of specific activity by introducing short time scale perturbations caused by, for example, the passage of a mesofront or convective showers. The time scale of these types of perturbation is relatively short; from 0.5 hours up to a maximum of 6 hours. These high frequency perturbations were filtered out of the observational data because the observed specific activities were given as daily averages.

The analysis of Fig. 5a indicates a very good coherence between specific activities observed at the surface and predicted values at the anemometer level. The predicted time variations of the specific activity are reproduced very well throughout the simulation. It is remarkable that the prediction of the time of arrival of radioactivity in Stockholm as well as the simulation of the second maximum of activity are very accurate.
Analysis of the model results indicates that the radionuclides from the Chernobyl accident transported by a steady westerly flow reached Japan on May 3. This conclusion, drawn from the predictive model run corresponds very well to the abrupt increase of radioactivity of the surface air at Honshu Island reported by Higuchi et al. (1988). The quantitative model verification for Japan is depicted in Fig. 5b where measurements at Chiba are compared with the model results. The correspondence between the predicted and the observed times of arrival of the radionuclides is quite good.

The general pattern of transfer of the radioactive material from Chernobyl to North America is depicted in Fig. 6. The locations of the observation points are marked by black squares. The results of the numerical simulation shown in Fig. 6 indicate that the radioactive cloud appeared in the surface air over the southwestern states of the USA and northeastern Canada on May 6. The comparison of the activities of $I_{131}$ predicted by the model at the anemometer level $(\sigma=1)$ to the values obtained from the measurements taken at Vancouver and Moosonee (Northern Ontario, Canada) is de- 

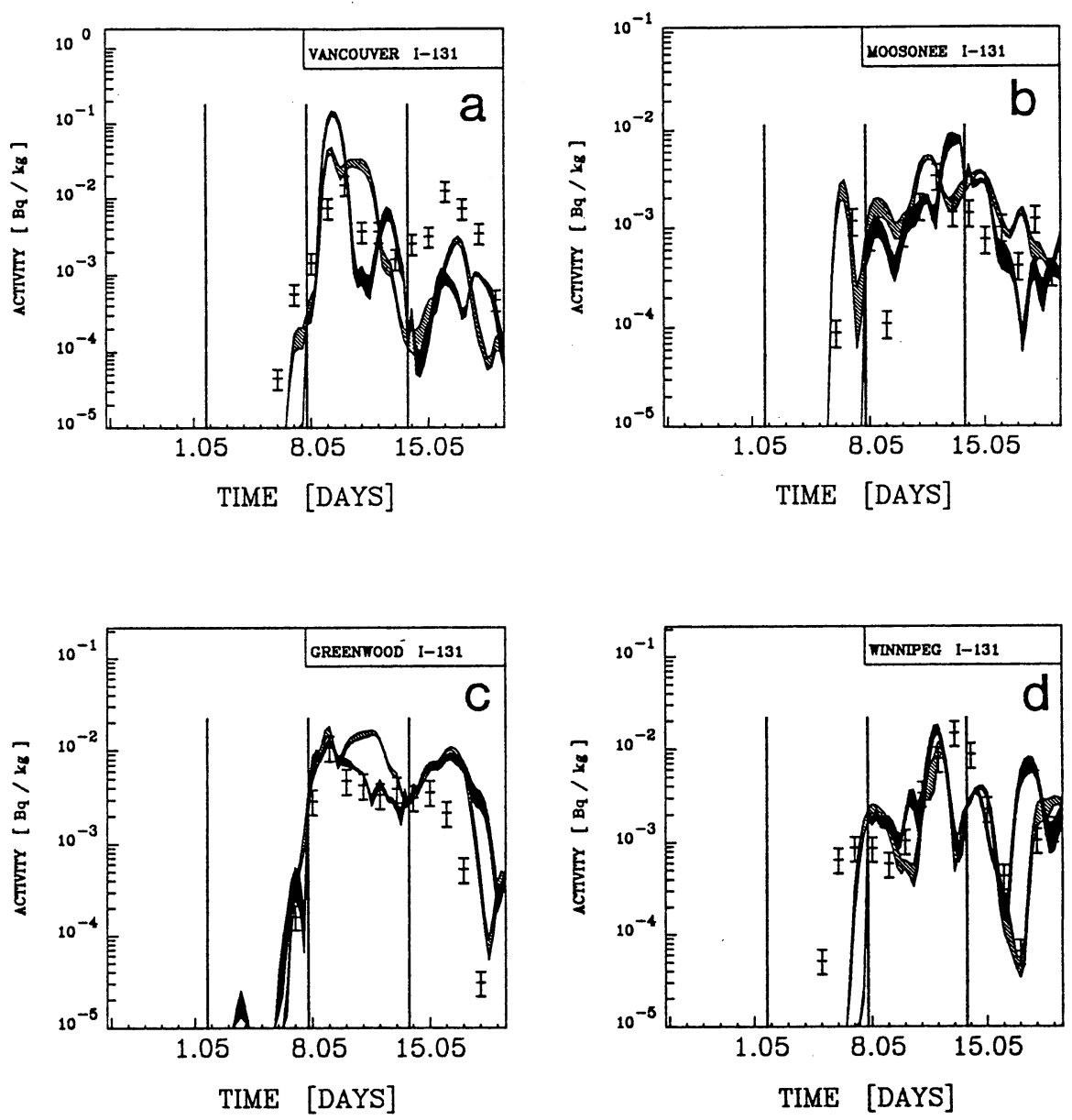

Fig. 7 . Comparison of the observed, diagnosed and predicted time series of I-131 activity in (a) Vancouver (British Columbia, Canada), b) Moosonee (Northern Ontario), c) Greenwood (Nova Scotia), d) Winnipeg (Manitoba).

picted in Fig. 7a, b. It is shown that for Vancouver the predictive model correctly simulates the general trends of specific activity, the time of arrival of the radioactive cloud and even the maximum values of activity. Concerning the model verification for Moosonee, there is a 2 day error in arrival time. However, the predicted time of arrival of the maximum values and the general trend of activity at this point are simulated correctly. The error in the prediction of the time of arrival of activity at Moosonee is a good illustration of the predictability problem for atmospheric tracers.

It is interesting to note that the radioactive cloud affected the Atlantic and Central parts of Canada at the same time as it affected the West Coast, namely on May 5 and 6 (Fig. 6a, b). The verification of the model for Atlantic and Central Canada is shown in Fig. 7c, d. It is evident that the predictive model is able to reproduce the initial Arctic injection of the radioactive material as well as the subsequent influence of the material transferred over the Atlantic Ocean.

In general the pattern of transfer of radioactive material from Chernobyl to North America was quite complex. The maximum values of the activity appeared in the surface air in different locations in North America at approximately the same time, namely on May 9 and May 10 (Fig. 6d). This effect can be largely attributed to the fact that the continent was affected by material travelling from across the Pacific as well as from the arctic regions and the Atlantic Ocean.

In fact, the occurrence of maximum activities of I-131 in North America coincided with the merging of the western, polar and Atlantic parts of the radioactive cloud (Fig. 6d). This process occurred as a result of horizontal advection and moreover was intensified by the subsidence of radioactive material in a high pressure system. This descent brought down to the surface material from higher levels where horizontal advection was much stronger than in the lower part of the troposphere. The large scale subsidence was therefore an important factor contributing to the observed times of arrival of the maximum activities. The time series for Chester (New Jersey), Ottawa, Calgary (Alberta) and Windsor (Ontario) depicted in Fig. 8 provide additional evidence of this fact. 

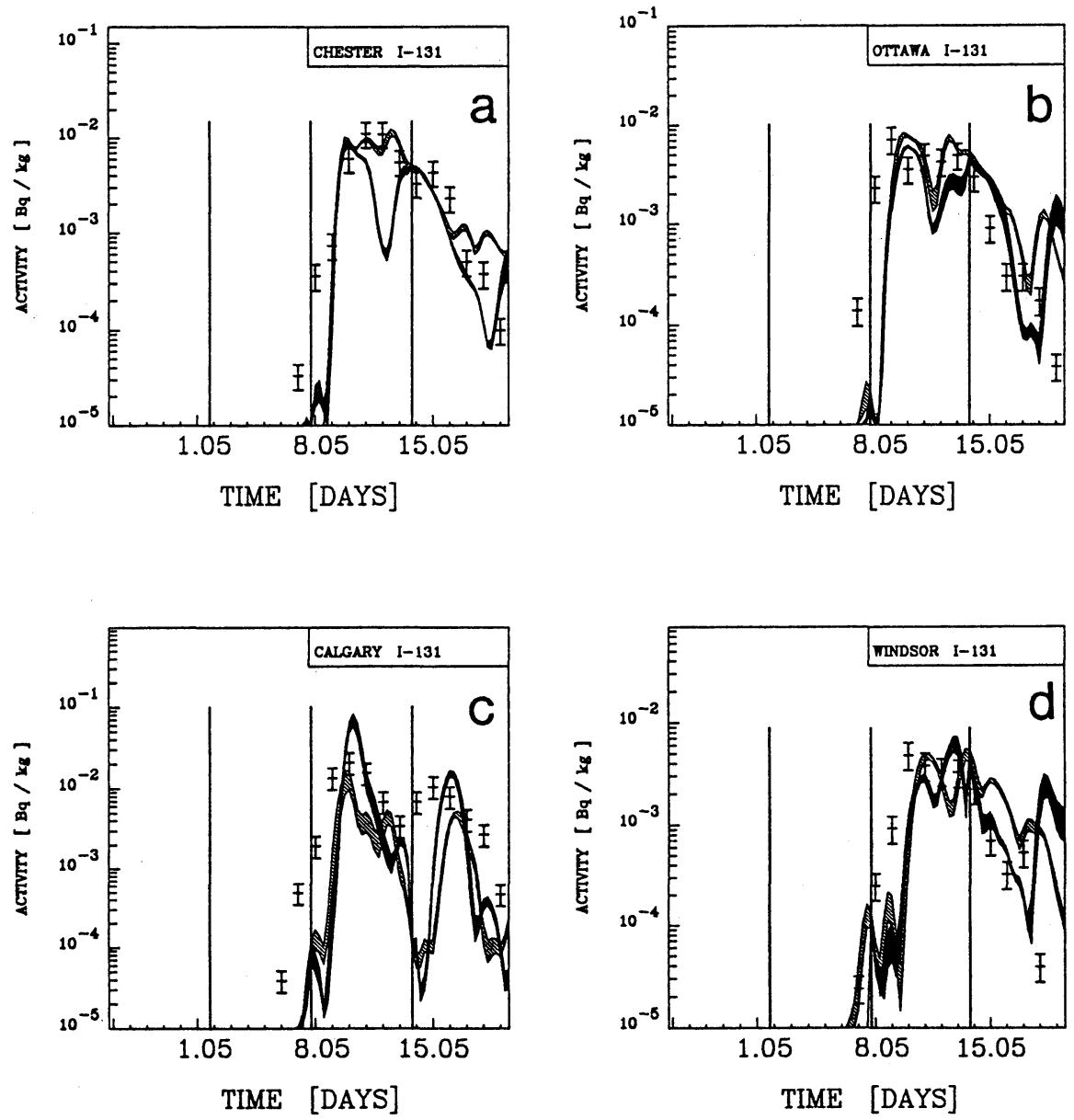

Fig. 8. Comparison of the observed, diagnosed and predicted time series of I-131 activity in (a) Chester (New Jersey, USA), b) Ottawa, c) Calgary, d) Windsor (Ontario, Canada).

The verification of the predictive model for Canadian and American stations presented in Figs. 5, 7 and 8 clearly shows that the numerical results are quite accurate. Moreover, the predicted times of arrival and the times of arrival of maximum activity agree quite well with the observed values and the parallel run of the diagnostic model.

\section{Conclusions}

The results presented in this paper indicate that the large scale distribution of an atmospheric tracer can be successfully predicted for up to 6 days. The selection of 6 days as a maximum prediction time, after which meteorological fields are updated from observation and the tracer field is updated from a parallel diagnostic run, is dictated by the observed performance of the spectral model. Prediction of the tracer distribution beyond the 6 day limit starts to deteriorate rapidly. In most practical applications with real data, this limit is quite reasonable.

At this moment, the system described by Eqs. (8)(14) is used operationally at the Canadian Meteorological Centre for simulation of the radioactive and chemical tracers on a regional and hemispheric scale. The system is employed additionally for the tracking of material released into the atmosphere by volcanic eruptions.

We believe that in the case of future nuclear emergencies, the role of predictive meteorology will be more prominent than in the past. The numerical models available currently are sufficiently accurate for synoptic scale and hemispheric scale applications. Problems related to the simulation on the mesoscale remain to be solved. The most critical areas to be addressed in this research are related to the improvement in the representation of the complex structure of precipitation systems and the enhancement of the parameterizations of chemical processes and wet scavenging in the tracer model.

\section{Acknowledgements}

The author wants to express his gratitude to $\mathrm{Dr}$ P. Merilees for his suggestion to perform this study. Discussions with D. Shantz of CMC were very helpful to prepare the runs of the spectral model used in this project. Thanks are also due to Mr. Bruce Brasnett of CMC who read a draft of this paper. 


\section{References}

Chamberlain, A.C. and R.C. Chadwick, 1966: Transport of Iodine from Atmosphere to Ground. Tellus, 18, 226-237.

Concus, P., G.H. Golub and D.P. O'Leary, 1976: A Generalized Conjugate Gradient Method for the Numerical solution of Elliptic Partial Differential quations. Rep. No. STAN-CS-76-533, Computer Sci. Dep., Stanford University.

Daley, R., C. Girard, J. Henderson and I. Simmonds, 1976: Short-Term Forecasting with a Multi-Level Spectral Primitive Equation model. Atmosphere, 14, 98-134.

Higuchi, H., H. Fukatsu, T. Hashimoto, N. Nonaka, K. Yoshimizu, M. Omine, N. Takano and T. Abe, 1988: Radioactivity in surface air and precipitation in Japan after the Chernobyl accident. J. Env. Radioactivity, 6, 131-144.

Kasahara, A., 1977: Computational aspects of numerical models for weather prediction and climate simulation. Methods in Computational Physics, 17, 2-60.

Kimura, F. and T. Yoshikawa, 1988: Numerical Simulation of Global Scale Dispersion of Radioactive Pollutants from the Accident at the Chernobyl Nuclear Power Plant. J. Meteor. Soc. Japan, 66, 489-495.

Kuo, H.L., 1974: Further studies of the parameterization of the influence of cumulus convection of the largescale flow. J. Atmos. Sci., 31, 1232-1240.

Pudykiewicz, J., R. Benoit and Staniforth A., 1985: Pre- liminary Results from a partial LRTAP model based on existing meteorological model. Atmos. and Ocean, 23, 283-308.

Pudykiewicz, J., 1988: Numerical Simulation of the transport of Radioactive Cloud from the Chernobyl Nuclear Accident. Tellus, 40B, 241-259.

Pudykiewicz, J., 1988: Simulation of the Chernobyl dispersion with a 3 -D hemispheric tracer model. Tellus, 41B 391-412.

Ritchie, H., 1985: Application of a semi-Lagrangian integration scheme to the moisture equation in a regional forecast model. Mon. Wea. Rev., 113, 424-435.

Ritchie, H., 1987: Semi-Lagrangian advection on a gaussian grid. Mon. Wea. Rev., 115, 608-619.

Robert, A., 1982: A semi-Lagrangian and semiimplicit numerical integration scheme for the primitive meteorological equations. J. Meteor. Soc. Japan, 60, $319-325$.

Rutherford, I.D., 1977: An Operational 3-Dimensional Multi- Variate Statistical Objective Analysis Scheme. Notes Scientifiques and Techniques, Division de Recherche en Prevision Numerique, Montreal, Canada.

Sundqvist, H., 1981: Prediction of Stratiform Clouds: Results from a 5-day forecast with a global model. Tellus, 33, 242-253.

Takasugi, T. and H. Nakamura, 1988: A tracer diffusion model coupled with JMA spectral model. Japan Meteorological Agency, Numerical Prediction Division Technical Report, Tokyo, Japan.

\title{
大気トレーサーの予報モデル \\ J. Pudykiewicz \\ （カナダ大気環境庁）
}

\begin{abstract}
大気中での輸送過程と対流圏・成層圏における大気科学過程をシュミレートできる全球規模のトレーサー 分布子報モデルについて述べる。モデルは全球スペクトルモデルと反応式を組み入れた物質の保存式から 成る。このモデルにより、チェルノブイリ事故による放射能物質が半球規模に抎散した事象を、再現モー ドと完全予報モードの両方のモードでテスト計算した。予報モードの結果の解析によると、十分な精度を 持つ初期值から出発すれば、物質分布の大規模な構造を 6 日間まで予測するてとが可能であるととが示さ れた。半球規模のトレーサー分布につレて 24 日間の延長予報も行われたが、6 日ごとに再現モデルにより 得られたトレーサー分布を新たな初期值として与えた。
\end{abstract}

